\title{
Neurotrophic interactions in the nervous system
}

\author{
Work group chairman: I. Black ${ }^{1}$ \\ Report prepared by: A. Mizisin ${ }^{2}$ \\ ${ }^{1}$ Robert Wood Johnson Medical School, University of Medicine and Dentistry of New Jersey, Piscataway, New Jersey; ${ }^{2}$ Department of \\ Neuropathology, School of Medicine, University of Califomia, San Diego, Califomia, USA
}

Summary. Traditional views have suggested that information flow in the nervous system is dependent on millisecond-to-millisecond communication occurring in a point-to-point manner. However, recent evidence suggests that growth and trophic functions are central to development and maintenance of function in the brain. In turn, trophism occurs over days to weeks to months and appears to underlie processes as diverse as learning, memory and development, on the one hand, and the pathogenesis of disease, on the other. This work group focussed on molecular and cellular mechanisms underlying trophic function in the brain.

Key words: Trophic factors, neurotrophin gene family, neurotrophin receptors.

\section{Introduction}

Growth signals and trophic signals elicit mitosis, growth and survival of neurons in the central and peripheral nervous systems. The recent realisation that growth and trophic signals are central to brain function has prompted the emergence of a number of central questions that constituted the subject of the present workshop. What is the functional relationship among the different members of the neurotrophin gene family, and among neurotrophins and other trophic and growth factors in the nervous system? How is functional specificity conferred on individual members of the neurotrophin gene family? Can we delineate functional relationships among subunits of trophin receptors? What cellular populations in the nervous system respond to different trophic factors and what is the biological readout? How is trophic factor gene expression regulated in the nervous system, and what are the relationships among trophic factors, neurotransmitters, growth factors and impulse activity?

Employing a combination of molecular, cellular, tissue culture and in vivo approaches, members of the work group addressed the foregoing questions. The neurotrophin gene family was provisionally defined. Receptor interactions were delineated. The origin of trophic factors in distant targets of innervation and in local populations was defined. Moreover, conferees agreed that trophic factors are necessary for normal function, but may also contribute to the pathogenesis of brain disease under conditions of derangement. Nevertheless, there was general accord that trophic factors possess therapeutic potential. Indeed, the judicious combination of gene transfer techniques, grafting of cellular populations to the brain and the induced elaboration of trophic factors represent a promising therapeutic avenue.

In this brief review, these topics are reviewed in sequence. Although our information remains fragmentary, we are now able to formulate relevant questions and even mechanisms of action in increasingly precise molecular terms.

\section{Classes of trophic factors in the nervous system}

Diverse molecules appear to subserve growth and trophic factors in the nervous system. Thus, for example, neurotransmitter and peptide molecules as different as nerve growth factor (NGF), ciliary neurotrophic factor (CNTF) and the neurotrophins, in general, have been defined in neural systems [1]. In particular, the neurotrophin gene family has been the focus of recent, intense interest [2]. Presently, the neurotrophin family includes four or five members that have been characterised to varying degrees including NGF, the most extensively studied, brain-derived neurotrophic factor (BDNF), neurotrophin-3 (NT-3), neurotrophin-4 (NT-4) and potentially neurotrophin- 5 (NT-5). The mature forms of these neurotrophins are highly basic peptides containing approximately 120 amino acids and cysteine residues that allow intrachain linkage by three disulphide bonds. Despite 
the fact that the neurotrophin family shares a $50 \%$ homology in amino acid sequence, each exerts its effect on different populations of neurons. For example, basal forebrain cholinergic neurons and mesencephalic dopaminergic neurons are responsive to different trophic agents.

\section{Neurotrophic receptors}

Two broad classes of neurotrophin receptors have been characterised by ligand association kinetics and molecular weight. The p75NGFR (nerve growth factor receptor) is characterised by relatively low affinity $\left(\mathrm{Kd}=10^{-9} \mathrm{~mol} / \mathrm{l}\right)$, which has been attributed to rapid dissociation. The low affinity moiety has an apparent molecular mass of $75 \mathrm{kDa}$. The intracellular domain encodes no apparent transduction mechanism but appears to contain a G-protein-binding consensus sequence. The high affinity species, denoted as trk, has an apparent molecular mass of $140 \mathrm{kDa}$ and is characterised by high-affinity binding $\left(\mathrm{Kd}=10^{-11} \mathrm{~mol} / \mathrm{l}\right)$ [36]. The cytoplasmic portion of the trk molecule contains a tyrosine kinase catalytic domain [7].

The precise constitution of the functional, high-affinity, biologically active neurotrophin receptor remains controversial. Chao and colleagues [4] have suggested that the biologically active receptor consists of an association of p75NGFR and a trk moiety. In contrast, Barbicid and others [5] have raised the possibility that trk alone represents the functional, high-affinity receptor. Since model systems have been as diverse as NIH 3T3 cells, $\mathrm{PC} 12$ phaeochromocytoma cells and primary neurons, definitive conclusions are not warranted at present. It is even possible, for example, that the molecular constitution of the receptor differs in different cell populations.

Finally, the molecular characteristics conferring receptor specificity for particular neurotrophins have yet to be defined. While specific trk molecular subspecies may confer specificity for individual members of the neurotrophin family, additional evidence is required for definitive interpretation. The issue of specificity is of fundamental biological importance, since effects as diverse as mitogenesis, cell survival and neurite outgrowth have been attributed to different members of the neurotrophin gene family. The nature of the ligand-receptor interactions, and the cellular contexts responsible for these different biological readouts remain to be elucidated.

\section{trk receptor structure}

The extracellular domain of the mammalian trk family is multifunctional, potentially containing binding domains for diffusible and fixed ligands. The extracellular portion of the molecule contains a terminal cysteine cluster that is separated from a second cysteine cluster by a leucine motif. An IgG domain lies adjacent to the plasma membrane. The precise sequence of the intracellular tyrosine kinase domain varies among members of the trk family. Nevertheless, all members of the trk family apparently undergo autophosphorylation, and presumably phosphorylate other proteins within the cell as they participate in the primary signal transduction mechanism of the neurotrophin gene family [3]. Differences in structure of the extracellular and intracellular domains presumably confer specificity of ligand interaction and cellular response.

\section{Structure-activity relationships: NGF as a model trophic factor}

Persson and colleagues [8] utilised site-directed mutagenesis and alanine scanning to characterise structureactivity relationships of NGF. In summary, lysines 32,34 and 95 are critical for binding and biological activity. In conjunction with the recently deduced X-ray crystallographic structure of NGF [9], the mutagenesis studies predict that the NGF binding site consists of a positively charged surface which interacts with negative moieties on the receptor. Moreover, use of mutagenised NGF revealed that low-affinity binding and biological activity are dissociable.

\section{Sources of trophic factors in the organism}

While previous formulations suggested that target structures elaborated trophic factors exclusively, it is now apparent that factor elaboration is far more widespread. Extensive evidence indicates that cells in the local environment express trophic factor genes and synthesize the active polypeptides. For example, local glia express the NGF gene in the hippocampus and in the cerebellum, structures which contain responsive neurons $[10,11]$. Moreover, Persson and colleagues [12] and Lindsay and colleagues [13] have found that BDNF and the appropriate receptor are expressed locally in the hippocampus. Consequently, converging lines of evidence indicate that trophic factors mediate local, proximate interactions as well as target-neuron interactions. Furthermore, Hendry suggested that agents such as fibroblast growth factor (FGF) may act through humoural mechanisms rather than exerting their action by retrograde axonal transport [14]. It may be concluded that trophic interactions occur through endocrine, paracrine and cven, potentially, autocrine mechanisms.

Nevertheless, targets do, indeed, constitute an important source of trophic factors. Target-trophic messages have been thought to bind to innervating nerve terminals, become internalised and undergo retrograde transport to the neuron cell body. Presumably, critical interactions with the neuronal nucleus occur after retrograde transport. However, as pointed out by Hendry at this conference, precise mechanisms underlying retrograde signal transduction have yet to be elucidated. Retrograde transport 
may involve a labile second messenger associated with a vesicle that arrives at the cell body as part of a large, information-carrying complex [15]. Elucidation will require development of appropriate in vivo and in vitro models.

\section{Regulation of trophic factor expression}

Although evidence remains fragmentary, multiple mechanisms governing trophic expression have already been defined. Different classes of mechanism may well govern trophic expression in different cellular populations.

Accumulating evidence suggests that impulse activity itself governs expression of the NGF gene by hippocampal neurons [16]. For example, depolarising influences elicit NGF gene expression in dissociated hippocampal neurons cultured in fully defined medium. In parallel studies performed in vivo, seizure activity increases BDNF mRNA in hippocampus $[17,18]$. Glutamatergic mechanisms appear to be responsible, at least in part, for depolarisationinduced trophic factor gene expression [2]. Regardless of the specific molecular mechanism, regulation of trophic expression by impulse activity could scarcely be of more importance. This represents a mechanism by which the nervous system may convert millisecond-to-millisecond electrical information into long-lasting changes that persist for days to weeks. The potential implications for pathway strengthening, and learning and memory need not be stressed.

Glia also express trophic factors. More specifically, astrocytes in culture and in vivo express the NGF gene. Recent evidence indicates that actively growing astrocytes turn on the NGF gene [11]. Gage at this conference described studies indicating cytokines turn on the NGF gene in glia [19], in agreement with the work with Friedman and colleagues [20], indicating that interleukin-1 beta increases NGF gene expression. Injury-induced glial activation in vivo elicits NGF gene re-expression in optic nerve, raising the possibility that trophic mechanisms may potentially contribute to restitution of function in the mature nervous system [11]. In summary, we are just beginning to understand the multiple mechanisms that govern trophic factor gene expression and peptide elaboration.

\section{Trophic factors and neuronal life and death}

PC12 phaeochromocytoma cells have proven to be a useful model for investigation of cell death resulting from trophic factor deprivation [21]. NGF deprivation results in cell death in the $\mathrm{PC} 12$ culture system after just 3 hours. Cell death is associated with fragmentation of DNA resulting from endonuclease activity. DNA fragmentation is a rapid and acute apoptotic response to as little as 1.5 hours of NGF deprivation. The apoptosis does not require extracellular $\mathrm{Ca}^{2+}$, in contrast to glutamatergic-mediated cell death. Moreover, the expression of new genes is not required, implicating a constitutive mechanism.

Aurintricarboxylic acid, a potent nuclease inhibitor, supports survival in the absence of NGF. These observations suggest that endonuclease mediates the DNA fragmentation and apoptosis consequent to NGF deprivation. On this basis, it may not be necessary to posit the existence of so-called suicide genes or proteins in the mediation of death following trophic deprivation.

\section{Therapeutic potential of neurotrophic factors}

The known neurotrophic factors support the survival of specific peripheral and central nervous system neurons in vitro [2]. NGF, BDNF and CNTF rescue neurons from naturally occurring developmental cell death in ovo. NGF and CNTF rescue axotomised neurons in perinatal rats, while NGF alone can rescue axotomised peripheral and central nervous system neurons in adult rats. NGF is capable of ameliorating memory loss in aged rats [22]. These actions argue for a role of trophic factors in physiological function during development and in the adult. The lack of animal disease models has hampered evaluation of trophic factor replacement therapy. However, mouse models are being used to explore the therapeutic potential of CNTF in motor neuron disease. Virtually all conference participants are developing new models of neuropsychiatric disease.

\section{Neuronal regeneration in the brain}

Gage and colleagues have examined the use of brain grafts to induce regeneration after lesions [23]. Specifically, they have studied the cholinergic, septohippocampal system after fimbria-fornix trans-section. This lesion axotomises the cholinergic pathway, depriving the hippocampus of its normal cholinergic innervation. Gage grafted fibroblasts containing a transfected NGF gene to the wound cavity lying between the septal cell bodies and the hippocampal field of innervation. The fibroblasts, secreting NGF, become invested by astrocytes. In turn, cholinergic fibres invade the graft and can be identified by acetylcholinesterase and IgG 192 positivity. Remarkably, the cholinergic fibres grow through the graft and form synaptic contacts with hippocampal neurons. This exciting work raises the possibility that functional regeneration may occur in the septohippocampal system. Physiological and behavioural studies are now in progress to determine whether functional restitution can in fact be induced.

\section{The trophic-toxic connection}

Cotman described studies using beta-amyloid peptide that hint at the complexity of trophic and degenerative 


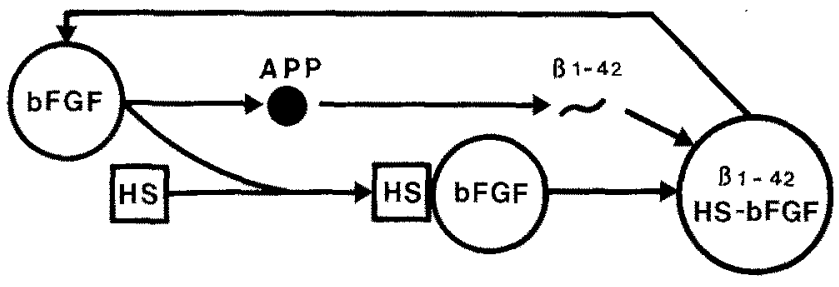

Fig. 1. Feed-forward loop involving basic fibroblast growth factor (bFGF), heparan sulphate (HS), amyloid precursor protein (APP) and $\beta 1-42$ peptide. In this model, bFGF, facilitated by HS, induces APP production and the subsequent formation of $\beta 1-42$ peptide which associates with bFGF and HS during plaque formation. In tum, $\beta 1-42$ peptide feeds back on bFGF pathways by upregulating its production (redrawn after [26])

processes. Under different circumstances, $\beta 1-42$ peptide may be either trophic or toxic. For example, the peptide elicits neurite growth in fresh cortical cultures and exhibits no toxicity when employed alone. However, in the presence of subthreshold concentrations of glutamate, exposure to beta amyloid results in cell death [24]. Moreover, the peptide appears to potentiate the damaging effects of decreased glucose and of ischaemia. Glutamate excitotoxicity may constitute the final damaging pathway.

In extremely provocative experiments, Cotman and colleagues have found that the hydrophobic regions of $\beta 1$ 42 peptides form insoluble aggregates upon storage [25]. The peptide aggregates, up to $20 \mathrm{kDa}$, appear to be toxic to neurons. Moreover, bFGF and heparan sulphate are associated with beta amyloid in senile plaques. Cotman envisions a deadly feed-forward loop in which FGF increases the synthesis of amyloid precursor protein resulting in increased formation and precipitation of $\beta 1-42$ peptide, heparan sulphate accumulation and increased FGF itself (Fig. 1). In this manner, $\beta 1-42$, bFGF and heparan sulphate may be involved in a self-potentiating destructive plaque formation that results in progressive degenerative disease. Since plaque formation has been observed in stroke, closed head trauma and even hypoglycaemia, this series of pathologic events may contribute to the pathogenesis of diverse disorders.

\section{Conclusions and recommendations}

While progress has obviously been explosive, many of the questions raised in the Introduction remain, though our focus has been sharpened. It may be useful to the reader to re-articulate some of the more pressing questions: To what degree are individual trophic factors sufficient for normal function? To what degree are combinatorial actions required for physiological responses? How many brain trophic factors remain to be identified? Do all brain neuronal populations require trophic support? Can we identify epigenetic factors that regulate trophic factor gene expression? How will the answer to the latter question ultimately influence therapeutic prospects?
Acknowledgements. This report is the result of Work Group 3: Brain and Peripheral Nerves at the Third JDF World Conference on Diabetes in Monte Carlo, Monaco, 8-10 March 1992. Chairman: I. Black. Work group participants: M. Chao', C. Cotman' ${ }^{2}$, C. Dreyfus ${ }^{3}$, F. Gage ${ }^{4}$, L. Greene', F. Hefti 6 , I. Hendry", R. Lindsay", H. Persson', E. Shooter ${ }^{10}$. Rapporteur: A. Mizisin. Discussant: S. Carbonetto".

Department of Cell Biology and Anatomy, Comell University Medical College, New York, New York, USA; 2Department of Psychobiology, University of Califomia, Irvine, Califomia, USA; ${ }^{3 R o b e r t}$ Wood Johnson Medical School, University of Medicine and Dentistry of New Jersey, Piscataway, New Jersey, USA; 'Department of Neuroscience, University of California, San Diego, California, USA; Department of Pathology, College of Physicians and Surgeons, Columbia University, New York, New York, USA; 'Andrus Center, University of Southem California, Los Angeles, California, USA; 'Division of Neuroscience, Australian National University, Canberra, Australia, Regeneron Pharmaceuticals, Tarrytown, New York, USA; ' 'Laboratory of Molecular Neurobiology, Department of Medical Chemistry, Karolinska Institute, Stockholm, Sweden; 'Department of Neurobiology, Stanford University, Stanford, Califomia, USA; "Center for Research in Neuroscience, McGill University, Montreal, Quebec, Canada.

\section{References}

1. Black IB, DiCicco-Bloom E, Dreyfus CF (1991) Nerve growth factor and the issue of mitosis in the nervous system. Curr Top Dev Biol 24: 161-192

2. Thoenen $H$ (1991) The changing scene of neurotrophic factors. TINS 14: 165-170

3. Kaplan DR, Hempstead BL, Martin-Zanca D, Chao MV, Parada LF (1991) The trk proto-oncogene product: a signal transducing receptor for nerve growth factor. Science 252: 554-558

4. Hempstead BL, Martin-Zanca D, Kaplin DR, Parada LF, Chao MV (1991) High-affinity NGF binding requires coexpression of the trk proto-oncogene and the low-affinity NGF receptor. Nature 350: 678683

5. Klein R, Jing S, Nanduri V, O'Rourke E, Barbacid M (1991) The trk proto-oncogene encodes a receptor for nerve growth factor. Cell 65 : 189-197

6. Loeb DM, Maragos J, Martin-Zanca D, Chao MV, Parada LF, Greene LA (1991) The trk proto-oncogene rescues NGF responsiveness in mutant $\mathrm{NGF}$-nonresponsive PC12 cell lines. Cell 66: $961-966$

7. Meakin SO, Shooter EM (1991) Tyrosine kinase activity coupled to high-affinity nerve growth factor-receptor complex. Proc Natl Acad Sci USA 88: $5862-5866$

8. Ibanez CF, Ebendal T, Barbany G, Murray-Rust J, Blundell TL, Persson $H$ (1992) Disnuption of the low affinity receptor-binding site in NGF allows neuronal survival and differentiation by binding to the trk gene product. Cell 69: 1-20

9. McDonald NQ, Lapatto R, Murray-Rust J, Gunning J, Wlodawec A, Blundell TL (1991) New protein fold revealed by a $2.3-\AA$ resolution crystal structure of nerve growth factor. Nature 354: 411-414

10. Lu B, Buck CR, Dreyfus CF, Black IB (1989) Expression of NGF and NGF receptor mRNAs in the developing brain: evidence for local delivery and action of NGF. Exp Neurol 104: 191-199

11. Lu B, Yokoyama M, Dreyfus CF, Black IB (1991) NGF expression in actively growing brain glia. J Neurosci 11: $318-326$

12. Emfors P, Wetmore C, Olson L, Persson H (1991) Identification of cells in rat brain and peripheral tissues expressing mRNA for members of the nerve growth factor family. Neuron 5: 511-526

13. Maisonpierre PC, Belluscio L, Friedman B et al. (1991) NT-3, BDNF and NGF in the developing rat nervous system: parallel as well as reciprocal pattems of expression. Neuron 5: 501-509

14. Hendry IA, Belford DA (1991) Lack of retrograde axonal transport 
of the heparin-binding growth factors by chick ciliary neurons. Int J Dev Neurosci 9: 243-250

15. Hendry IA, Crouch MF (1991) Retrograde axonal transport of the GTP-binding protein Gia: a potential neurotrophic intra-axonal messenger. Neurosci Let 133: 29-32

16. Lu B, Yokoyama M, Dreyfus CF, Black IB (1991) Depolarising stimuli regulate nerve growth factor gene expression in cultured hippocampal neurons. Proc Natl Acad Sci USA 88: 6289-6292

17. Emfors P, Bengzon J, Kokaia Z, Persson H, Lindvall O (1991) Increased levels of messenger RNAs for neurotrophic factors in the brain during kindling epileptogenesis. Neuron 7: $165-176$

18. Gall CM, Isackson PJ (1989) Limbic seizures increase neuronal production of messenger RNA for nerve growth factor. Science 245: 758-761

19. Yoshida K, Gage FH (1992) Cooperative regulation of nerve growth factor synthesis and secretion in fibroblasts and astrocytes by fibroblast growth factor and other cytokines. Brain Res 569: 14-25

20. Friedman WJ, Larkfors L, Ayer-LeLievre C, Ebendal T, Olson L, Persson H (1990) Regulation of beta-nerve growth factor expression by inflammatory mediators in hippocampal cultures. J Neurosci Res 27: $374-382$
21. Batistatou A, Greene LA (1991) Aurintricarboxylic acid rescues PC12 cells and sympathetic neurons from cell death caused by NGF deprivation: correlation with suppression of endonuclease activity. $J$ Cell Biol 115: 461-471

22. Fisher W, Bjorklund A, Chen K, Gage FH (1991) NGF improves spatial memory in aged rodents as a function of age. J Neurosci 11: 1889-1896

23. Kawaja MD, Rosenberg MB, Yoshida K, Gage FH (1992) Somatic gene transfer of nerve growth factor promotes the survival of axotomised septal neurons and the regeneration of their axons in adult rats. J Neurosci 317: 102-116

24. Koh J, Yang LL, Cotman CW (1990) Beta-amyloid protein increases the vulnerability of cultured cortical neurons to excitotoxic damage. Brain Res 533: 315-320

25. Pike CJ, Walencewicz AJ, Glabe CG, Cotman CW (1991) In vitro aging of beta-amyloid protein causes peptide aggregation and neurotoxicity. Brain Res 563: 311-314

26. Cotman CW, Pike CJ, Cummings BJ (1993) Adaptive versus pathologic plasticity. Possible contributions to age-related dementia. In: Seil FJ (ed) Advances in neurology, Vol 59, Raven Press, New York 